\title{
Interactions of pinyon and juniper trees with tebuthiuron applications at 2 matched rein- vaded sites in Utah
}

\author{
NICHOLAS S. VAN PELT AND NEIL E. WEST
}

\begin{abstract}
Authors are land steward, The Nature Conservancy, P.O. Box 11486, Salt Lake City, Ut. 84147-0486; and professor, Department of Range Science, Utah State University, Logan, Ut. 84322-5230.
\end{abstract}

\section{Abstract}

Tebuthiuron \{N-[5-(1,1-dimethylethy])-1,3,4-thiadiazol-2-yl]-N, $\mathbf{N}^{\prime}$-dimethylurea\} controls small trees in regrown pinyon-juniper woodland chainings. Precise applications by hand minimize cost and damage to forage plants. Little information exists on the applicability of local trials to varying Intermountain sites slated for reinvestment. We conducted 2 balanced factorial experiments at well-separated sites in the Great Basin and Colorado Plateau. Four rates $\left(0.12,0.25,0.50\right.$, and $0.75 \mathrm{gm}$ a.j. per $130 \mathrm{dm}^{3}$ crown volume) of tebuthiuron boluses were applled to tree stembase, mid-crown, or dripline placements. Four size classes (12-99, 100-299, 300-599, and $600-1099 \mathrm{dm}^{3}$ crown volume) of Utah juniper [Juniperus osteosperma (Torr.) Little] and single needle (Pinus monophylla Torr. and Frem.), and Rocky Mountain (P. edulis Engelm.) pinyon trees were treated in September 1985. Defoliation and mortality levels were estimated 24 and 36 months following treatments. Both sites recelved highly similar amounts of herbicide and cumulative precipitation. Analysis of variance showed that the presence and strength of main effects and first order interactions was largely site-specific. Pinyon was more susceptible than juniper at either site. Medium-sized and large saplings were apparently more readily defoliated than seedlings and small saplings. Dosage effects were generally nonlinear for both species. The highest, most rapid and most uniform defoliation and mortality of trees resulted from application of tebuthiuron at the stem bases. This placement option has strong operational advantages and minimizes damage to forage plants beneath trees.

Key Words: pinyon, juniper, tebuthiuron, plant control, herbicidal trials

A location-by-treatment, species-by-treatment, or other kind of interaction results from many wildland experiments involving herbicides, fertilizers, soil amendments, or controlled burning (e.g., Clary, et al. 1985, Cook and Stubbendieck 1986, Herbel et al. 1985). For this reason, trials involving new species or sites, or both,

Approved as journal paper 4186 of the Utah Agricultural Experiment Station.

This publication reports research involving pesticides. It does not contain recommendations for this use, nor does it imply that the uses discussed herein have been registered. All uses of pesticides must be registered by appropriate state and/or federal agencies.

The authors wish to thank Eli Lilly and Company (ELANCO), Fresno, Calif., and Indianapolis, Ind., for supplying herbicide used in the experiments. Richard Bjerregaard of ELANCO originally suggested a factorial approach to devising treatment combinations. The USDI Bureau of Land Management (Salt Lake and Moab Districts) gave permission for use of the study sites. We are grateful to Barbara Daniels and Lynn McConville for assistance with field setups and data recording. David Hansen (formerly with the Moab District) and Lewis Munk (University of California, Davis) described soil profiles. Donald Sisson and Rex Hurst lent unstinting statistical advice throughout project conception, execution, and analysis.

Manuscript accepted 15 Mar. 1992 should be undertaken to test earlier results further, confirm generality, or adjust for interregional differences. Unfortunately, most field experiments are not designed to assess geographical generality (Pearce and Brown 1983). A related issue in applied ecology is "considering how spatial and temporal variability may influence the results of short-term experiments" (Gross 1989:264). Herbicidal trials generally last 1 to 3 years, and the prevailing weather may be atypical.

The efficacy of a herbicide depends on several factors (Scifres 1977), yet manufacturers and range managers often recommend and apply a uniform rate. An experimental procedure should be duplicated at numerous sites to determine whether the results of a treatment can be replicated in space or time. Expectations may be formulated as a priori hypotheses based on earlier research findings or long experience with a rangeland system (Provenza 1991).

Our study involved immature, noncommercial woodlands that are steadily reoccupying sites cleared to increase forage production. Our goal was the identification of optimal stand and treatment factors to defoliate trees. Saplings and seedlings invade or recover following 1960 s-era chainings or cablings of pinyonjuniper woodlands. Economical control could extend the benefits of previous investments on the land (West 1984). One option involves solid tebuthiuron (N-[S-(1,1-dimethylethyl)-1,3,4-thiadiazol-2-yl]-N,N'-dimethylurea\}. Hand application of this herbicide to individual trees reduces costs of materials per unit area (Van Pelt and West 1990). It also permits very precise placement on the ground surface. We compared the amount of defoliation from several combinations of placement and dosages of herbicide applied to an array of tree sizes. Two matched experiments were employed, 1 at each of 2 geographically and statistically independent sites. Analysis of variance (ANOVA), coupled with orthogonal contrasts, was the statistical tool used in conjunction with a fully balanced factorial design (Steel and Torrie 1980, Yang 1983).

Our hypotheses were that (i) tree species and size would strongly affect defoliation and mortality; (ii) defoliation and mortality would be linear for the application of equi-spaced tebuthiuron rates; (iii) placement-based differences would be very large, an expectation derived from the results of a related study (Van Pelt and West 1989); and (iv) differences evident early in the experiment among factor levels would later become insignificant. A supplementary, nonstatistical objective was to compare informally the response patterns between the 2 sites. This was done to derive an hypothesis for future resolution by chemical ecologists.

\section{Methods}

\section{Study Sites}

Our experimental locales clearly expressed salient climatic and soil characteristics of their ecoregions (Omernik 1987). Both have climatically variable, low-productivity rangelands. They chiefly 
differ in moisture regime, soil family, and flora. Utah juniper [Juniperus osteosperma (Torr.) Little] and Rocky Mountain (Pinus edulis Engelm.) or singleneedle pinyon ( $P$. monophylla Torr. \& Frem.) were the only tree species present, but each site had only 1 pinyon species. The experiments were 169 airline $\mathrm{km}$ apart.

Treatments at the 2 typical sites involved highly similar sets of trees, identical setup procedures, application dates separated by 1 day, and nearly simultaneous response recordings. Each had an abundance of small trees from which matched sets of experimental units were selected. In addition, the sites occurred on similar topography (bajadas on the western sides of steep, moderately high mountain ranges). They differed in soil type and summer rainfall. We scrutinized records from stations in the vicinity of each and isopleth maps for Utah, to confirm that the sites had historically similar average annual precipitation.

The Black Rock Canyon (BRC) site, $58 \mathrm{~km}$ southwest of Provo, Ut., is on gentle, planar slopes at $1,830 \mathrm{~m}$ on the northwest side of the East Tintic Mountains. It was chained in 1964. Annual precipitation averaged between 300 and $350 \mathrm{~mm}$, with most falling between December and March. Sporadic, generally low-intensity thunderstorms occurred in July, August, and September, but the climate was mainly summer-dry (Van Pelt and West 1989). The site was underlain by the Abela very gravelly loam, a fine-loamy over loamy-skeletal, mixed, mesic aridic calcic argixeroll (Van Pelt 1988). The site had a calcrete restricting layer and low production of herbaceous plants, constraining operational-scale retreatment. Singleneedle pinyon was the only pinyon species present.

The eastern site, East Carbon (EC), lies $33 \mathrm{~km}$ east-southeast of Price, Ut., at the base of the West Tavaputs Plateau. It was chained in 1966. The plots were at $1,980-\mathrm{m}$ elevation, on west and westsouthwest aspects. The long-term average precipitation was 300 to $350 \mathrm{~mm}$, with about half falling during December through April and the remainder often as intense summer thundershowers. Study plots were underlain by the Mivida and Strych soils, occupying about $80 \%$ and $20 \%$ of the treated area, respectively. The deeper Mivida soil was a coarse-loamy, mixed, mesic ustollic calciorthid (Soil Conservation Service 1988). In contrast to BRC, EC had appreciable grass. It would thus show a greater rejuvenation of forage following operational-scale tree removal.

\section{Selection of Trees, Dosage Rates, and Placements}

We conducted 4 plant-dimensional, soils, and herbicidal-outlay comparisons among the sets of trees and between the sites prior to and immediately following tebuthiuron applications. The factorial arrangement included 2 levels of species, 4 of tree canopy size, 4 dosage rates plus 2 untreated controls, and 3 sub-canopy placements. With the exception of pinyon species, the factors and levels were identical at the 2 sites.

Four ranges of estimated crown volume $\left(\mathrm{dm}^{3}\right)$ were selected from the tree sizes available at the sites. Nearly all trees were less than $200 \mathrm{~cm}$ high, a suggested upper limit for control operations (Clary et al. 1985), even though height was not an explicit variable. The classes were: $12-99,100-299,300-599$, and $600-1,099 \mathrm{dm}^{3}$ of crown volume. Crown volumes was chosen as the relevant size variable because it was easily and accurately estimated from linear stem and crown measurements. It also bears a strong correspondence to foliage mass and area (Tausch and Tueller 1988). Crown volume is the variable probably most related to tebuthiuron toxicity. Trees were all upright and vigorous, with no dead foliage. They were individually marked with aluminum tags, and were entirely independent in both the biological and statistical senses.

Four stepped rates of tebuthiuron were applied to evaluate the hypothesis of linear defoliation response. The rates were termed low (L), medium-low (ML), medium-high (MH), and high (H). Actual dosages within a rate were carefully scaled, in 9 increments, to estimated crown volume. Levels of placement were nominal, reflecting obvious choices for particle application beneath a tree. The stembase, a mid-crown, and "dripline" (canopy-margin) options also correspond to precipitation collection or herbicide placements used by others (Young et al. 1984, Van Pelt and West 1989).

We maintained 3 temporary and 2 permanent (over-winter) rain gauges at both sites from June 1985 to October 1987. The gauges were emptied at irregular intervals during the summers of 1985 , 1986,1987 , and 1988 as well as at the beginning and end of the water year. This procedure allowed comparison of cumulative precipitation at intermediate recordings as the experiment progressed.

Twenty-four surface (0-5 cm deep) soil samples were obtained at each of the 3 placements, beneath both juniper and pinyon at BRC and EC. The samples were submitted for laboratory analyses of texture and organic matter (Klute 1986). These characteristics influence the effectiveness and variability of tebuthiuron applications (Duncan and Scifres 1983).

\section{Experimental Design, Field Layout, and Application Procedure}

The $\mathbf{4 3 2}$ experimental units (individual trees) at each site were incorporated in a 2 (species) $\times 4$ (canopy sizes) $\times 6$ (rates plus controls) $\times 3$ (placements) balanced factorial, with 3 replications. However, the ANOVAs reported here include 4 factors of rate since the controls showed no defoliation and were not integral to the analysis. Controls were used in case a damaging natural agent caused discoloration of untreated trees during the course of the experiment. Therefore, the ANOVAs presented are for a $2 \times 4 \times 4$ $\times 3$ factorial with 3 replications. We completely randomized the field design, to avoid any restriction of a factor level to a particular plot with possible soil anomalies (Hurlbert 1984). All terms in the ANOVA were tested against error because that is the most conservative approach to take regarding real effects (Hurst 1986).

We located, measured, and tagged trees within rectangular, carefully diagrammed plots. Plots were generally aligned on the contour. Our selection of qualifying trees observed Hulbert's (1984) advocacy of randomization with interspersion of treatments, coupled with independence of experimental units.

We applied tebuthiuron formulated as Spike 250 "Brush Bullets"8 ( $0.25 \mathrm{~g}$ active ingredient) by hand on 24 and 25 September 1985 at EC and BRC respectively. Particles (boluses) were gently handplaced concentrically at 1 of 3 placements (dripline, midcrown, or at the stem base). The rates were structured in the ratios of 0.5: 1.0: 1.5 or 2.0 , with $\mathrm{ML}$ as the base $(1.0 \mathrm{x})$ rate of $0.25 \mathrm{~g}$ a.i. per $130 \mathrm{dm}^{3}$ of crown volume.

\section{Recording Procedure and Data Analysis}

We recorded tree responses to the tebuthiuron treatments 12,20 , 24,32 , and 36 months post-treatment. Response was considered as either dead, adhering needles, or defoliation. Defoliation was estimated as a percentage of the live crown volume. Two estimators reconciled their estimates at the 20 -month recording, and were in close agreement. Otherwise, the senior author performed all estimates. Almost all analyses below refer to the 24- and 36-month data. No control trees exhibited natural discoloration.

Tests of hypotheses followed standard ANOVA using an arc sin transformation (Hurst 1986), then linear contrasts among backtransformed means of simple and main effects. This transformation is appropriate for distributions of percentages with a wide range of values and/or with many very low and very high values. Contrasts are appropriate for analyzing experiments containing a variety of types and levels of treatment (Warren 1979, Steel and Torrie 1980, Mize and Schultz 1985).

\section{Results}

The assignment of trees to factor-level combinations, coupled 
with nearly identical total dosages at both sites, afforded a strong basis for minimizing error relative to hypothesized site, species, size, and treatment (rate and placement) differences. East Carbon was the drier site for the first 2 years post-application, but by 36 months the 2 locales were highly similar in accumulated precipitation amounts (Table 1). The quantities shown are of both rainfall and snowfall.

Table 1. Cumulative precipitation $(\mathrm{mm})$ at the sites, measured at each defoliation recording occasion.

\begin{tabular}{lcccccc}
\hline \hline \multirow{2}{*}{ Site } & \multicolumn{5}{c}{ Months since application } \\
\cline { 2 - 7 } & 8 & 12 & 20 & 24 & 32 & 36 \\
\hline \multirow{3}{*}{ Black Rock Canyon } & 373 & 443 & 688 & 755 & 990 & 1040 \\
East Carbon & 226 & 305 & 533 & 689 & 959 & 1049 \\
\hline
\end{tabular}

The primary means of demonstrating the careful matching of sets of trees was a supplemental ANOVA using estimated crown volume as the dependent variable (Van Pelt 1988:77-79). Size, which was deliberately varied among sets when trees were chosen, accounted for over $90 \%$ of total variance. After tebuthiuron applications, we also summed and compared numbers of boluses allocated to each site. The trees at EC received $6 \%$ less herbicide than those at BRC.

Soil textural analyses for BRC samples showed slightly more organic matter $(\mathrm{OM})$ at the stem base than at other placements, and averaged $6 \%$ for all trees. No differences in textural proportions were evident among placements. Clay content averages $12 \%$. At East Carbon, the least $\mathrm{OM}$ occurred at the dripline placement, and averaged 5\% for all trees. As at BRC, no differences in texture occurred among placements. Clay content averaged $9 \%$, with no differences detected among placements. Organic matter and texture probably did not influence overall response (Duncan and Scifres 1983) or placement differences.

At Black Rock Canyon, all main effects (factors) were significant after 24 months. However, they varied greatly in their importance and their participation in interactions (Table 2). Species was

Table 2. Comparative analyses of variance for percent defoliation response from the intermediate (24-month) and final (36-month) recordings at both sites.

BRC $=$ Black Rock Canyon $=$ EC $=$ Eust Carbon.

\begin{tabular}{|c|c|c|c|c|c|}
\hline \multirow[b]{2}{*}{ Source of variation } & \multirow[b]{2}{*}{ df } & \multicolumn{2}{|c|}{24 months } & \multicolumn{2}{|c|}{36 months } \\
\hline & & BRC & EC & BRC & EC \\
\hline & & \multicolumn{4}{|c|}{ F value } \\
\hline Species & 1 & $55.0^{* *}$ & $19.9^{* *}$ & $30.6^{* *}$ & $4.2^{* *}$ \\
\hline Size & 3 & $6.3 * *$ & $6.1^{* *}$ & $4.5^{* *}$ & $6.4 * *$ \\
\hline Species $\times$ Size & 3 & $<1.0$ & $<1.0$ & 1.8 & 2.5 \\
\hline Rate & 3 & $9.3 * *$ & $9.8^{* *}$ & $5.9 * *$ & $7.0^{* *}$ \\
\hline Species $\times$ Rate & 3 & $3.3^{*}$ & $<1.0$ & $3.9 * *$ & 0.8 \\
\hline Size $\times$ Rate & 9 & 1.3 & $3.2^{* *}$ & 0.7 & 0.8 \\
\hline Species $\times$ Size $\times$ Rate & 9 & $2.4^{*}$ & $3.2 * *$ & 0.7 & 0.2 \\
\hline Placement & 2 & $6.8^{* *}$ & $3.6^{*}$ & 2.4 & 1.6 \\
\hline Species $\times$ Placement & 2 & $3.7^{*}$ & 2.5 & 1.9 & 2.7 \\
\hline Size $\times$ Placement & 6 & $2.3^{*}$ & 1.7 & 1.2 & 1.4 \\
\hline Species $\times$ Size $\times$ Placement & 6 & 1.4 & $<1.0$ & 1.8 & 1.5 \\
\hline Rate $\times$ Placement & 6 & $<1.0$ & 1.4 & 0.8 & 0.6 \\
\hline Species $\times$ Size $\times$ Rate $\times$ & & & & & \\
\hline Placement & 6 & 1.8 & 1.8 & 1.7 & 0.5 \\
\hline Size $\times$ Rate $\times$ Placement & 18 & 1.6 & $<1.0$ & 1.0 & 0.3 \\
\hline Species $\times$ Size $\times$ & & & & & \\
\hline Rate $\times$ Placement & 18 & 1.3 & 1.5 & 1.3 & 0.8 \\
\hline Replications & 2 & $6.1^{* *}$ & $<1.0$ & 2.9 & 0.7 \\
\hline Error & 190 & - & - & - & - \\
\hline
\end{tabular}

*,**means significant at the 0.05 and 0.01 probability levels, respectively. clearly the most important effect, followed by rate. Size and placement were nearly equal in effect. Second-order (3-term) interactions were rarely significant after 24 and 36 months (Table 2). At either occasion, species differences contributed more to variance than any other source. Placement differences were at first highly significant, but became insignificant after 36 months.

At East Carbon after 36 months, species differences were not nearly as pronounced as at $\mathbf{2 4}$ months. Rate and size were the most influential factors. Differences between pinyon and Utah juniper response were not as great as at BRC. Never a strong source of variation, placement had become insignificant after 36 months.

Inasmuch as size and rate within a species were most important at 36 months (at both sites), means are arrayed correspondingly in Table 3. Defoliation usually increased with higher herbicide application rates for any species and rate combination (Table 3). Many

Table 3. Defoliation (\%) in 1988 at the East Carbon site (36-month recording). Within rows, means denoted by the same letter are not significantly different $(p>0.05)$.

\begin{tabular}{llccc}
\hline & \multicolumn{4}{c}{ Rate } \\
\cline { 2 - 5 } Species and size & Low & $\begin{array}{c}\text { Med. } \\
\text { Low }\end{array}$ & $\begin{array}{c}\text { Med. } \\
\text { High }\end{array}$ & High \\
\hline & & & & \\
Utah Juniper & $72 \mathrm{~b}$ & $48 \mathrm{a}$ & $83 \mathrm{~b}$ & $64 \mathrm{ab}$ \\
Size 11 & $65 \mathrm{a}$ & $60 \mathrm{a}$ & $88 \mathrm{~b}$ & $100 \mathrm{~b}$ \\
Size 2 & $77 \mathrm{a}$ & $82 \mathrm{a}$ & $98 \mathrm{a}$ & $89 \mathrm{a}$ \\
Size 3 & $88 \mathrm{a}$ & $89 \mathrm{a}$ & $100 \mathrm{a}$ & $99 \mathrm{a}$ \\
Size 42 & $75 \mathrm{ab}$ & $70 \mathrm{a}$ & $93 \mathrm{~b}$ & $88 \mathrm{~b}$ \\
Overall Mean & & & & \\
& & & & \\
Rocky Mountain Pinyon & $73 \mathrm{a}$ & $82 \mathrm{ab}$ & $94 \mathrm{ab}$ & $100 \mathrm{~b}$ \\
Size 11 & $71 \mathrm{ab}$ & $54 \mathrm{a}$ & $89 \mathrm{~b}$ & $86 \mathrm{~b}$ \\
Size 2 & $79 \mathrm{a}$ & $95 \mathrm{a}$ & $100 \mathrm{a}$ & $90 \mathrm{a}$ \\
Size 3 & $89 \mathrm{a}$ & $100 \mathrm{a}$ & $100 \mathrm{a}$ & $100 \mathrm{a}$ \\
Size 42 & $78 \mathrm{a}$ & $83 \mathrm{a}$ & $96 \mathrm{a}$ & $94 \mathrm{a}$ \\
Overall Mean & & & & \\
\hline
\end{tabular}

ISmallest size (12-99 $\left.\mathrm{dm}^{3}\right)$.

${ }^{2}$ Largest size $\left(600-1099 \mathrm{dm}^{3}\right)$.

adjacent rates (for example, $L$ and $M L$ ) were not significantly different, however. Other responses were nonmonotonic, or did not increase with a higher rate. Pinyon were slightly more susceptible than juniper of the same size class within a rate, but the difference was often not significant.

With few exceptions, trees of the 2 largest sizes were moderately more susceptible than smaller ones, a pattern true of both species here and at BRC (Table 3). Incidences of relatively low defoliation (about $70 \%$ or less) were confined to the 2 lowest rates and the smallest 2 tree sizes. Nearly all pinyon, but only the larger juniper, subjected to the highest 2 rates were dead within 3 years of application.

If tree sizes are ignored, the treatment (rate plus placement) choices available to an applicator comprise a two-way matrix for each species at each site (Fig. 1). A more divergent response of juniper is generally evident, as in the nearly complete defoliation achieved with singleneedle pinyon at the shallow-soil site (BRC). Highly effective and, conversely, ineffective options are readily seen (Fig. 1). The stembase in conjunction with 1 of the 2 higher rates is generally most effective. However, in several site-speciestreatment instances the choice of rate and placement is immaterial if 36 months are allowed to elapse.

\section{Discussion and Conclusions}

\section{Evaluation of Species and Size Differences}

Utah juniper was consistently more tolerant of tebuthiuron than the associated pinyon species, but no correlative explanation was evident. The difference is greatest at earlier recordings and becomes 
Juniper, BRC

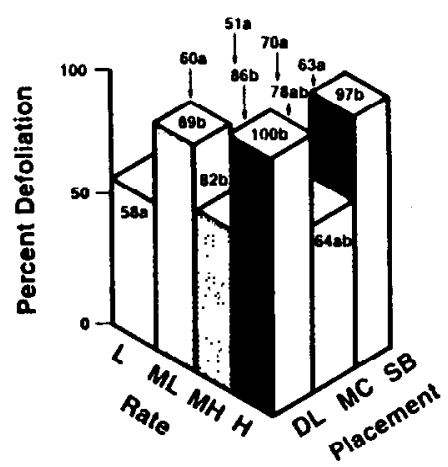

Pinyon, BRC

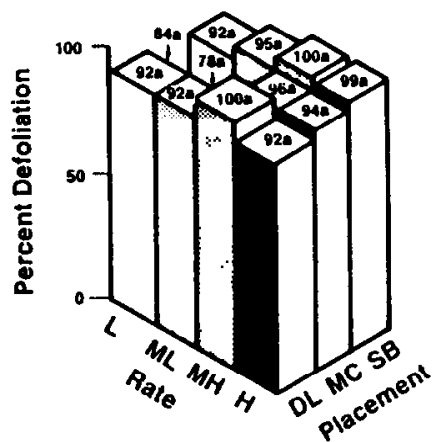

Juniper, EC

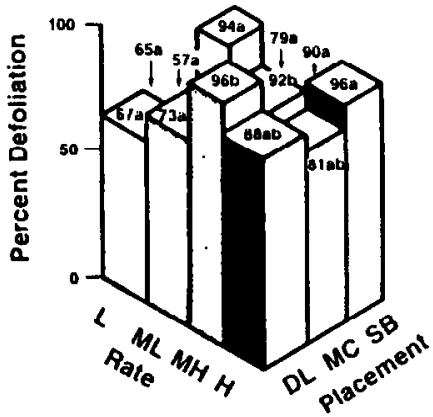

Pinyon, EC

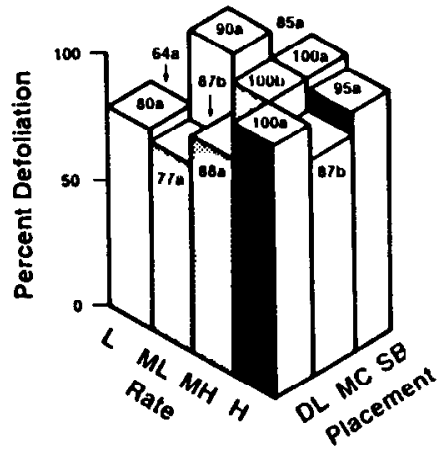

Fig. 1. Percent defoliation for dosage-rate and placement combinations, within each of the 4 species and site combinations. Within a placement, means denoted by the same letter are not significantly different $(p>0.05)$. BRC = Black Rock Canyon site; EC = East Carbon site; $D L=d r i p l i n e ; S B=$ stembase; MC = midcrown; $L$ = low; $M L=$ medium-low; $M H=$ medium-high; $H=$ high.

less as $\mathbf{3 6}$ months are approached. Neither a particular size nor a placement were responsible. Placing herbicide at the dripline, where interception of rainfall by the crown would be immaterial, did not override the difference. It is known that juniper has greater foliar mass (Tausch and Tueller 1988), but translocation physiology, metabolism, and leaf anatomy could also account for response differences. These were untested here.

Species-and-size combinations had a less clear trend of increasing effect with higher tebuthiuron rates. The smallest juniper class was anomalous because 2 higher rates had less effect than their

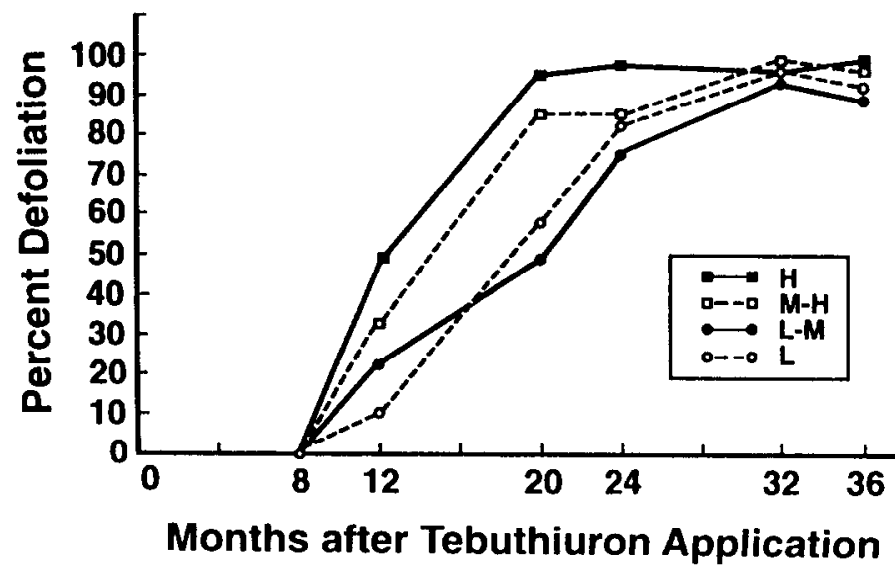

Fig. 2. Relative differences among the 4 rates of tebuthiuron application over the course of the experiment, in response to the stembase placement. Trees of all species and sizes at the East Carbon site comprise each curve. $\mathbf{L}=$ low; $\mathbf{L}-\mathbf{M}=$ medium-low; $\mathbf{M}-\mathbf{H}=$ medium-high; $\mathbf{H}=$ high. adjacent, lower levels (Table 3). The averages for all sizes for each species had small (5-10\%), often nonsignificant differences among rates. Differences between juniper (all sizes) and pinyon (all sizes) were slight for any rate, but pinyon was still more susceptible. The disparity between large and small trees might be less if dosages were scaled to height. Doing so is a much less time-consuming and tedious operational practice, anyway (Van Pelt and West 1990). Some intersize differences may have resulted from the width of the crown-volume classes that we defined. Too few trees were available to enable use of narrower class limits while still achieving experimental balance.

\section{Effective and Robust Treatment Combinations}

After 36 months, all but 1 of the rates used with the stem base placement at East Carbon yielded $90 \%$ or greater defoliation of both species (Fig. 1). The stem placement was similarly effective with pinyon at BRC. However, only the highest rate resulted in $90 \%$ or greater defoliation, with any placement, of juniper at BRC. The midcrown and dripline placements were frequently effective, but usually only when employed with the high and medium-high rates. If only 1 rate can be specified for tebuthiuron use at these and similar sites, it should be the highest $(H)$, applied only to the stembases (SB) of all pinyon and juniper trees. For some site-andspecies combinations, a lower rate will work if used at the stem base.

However, controlling juniper on Great Basin chainings with shallow-soil sites will require applying the highest rate, again at the stem base. That is, juniper on such sites will require greater inputs and will exhibit more variable response than pinyon. Damage to undergrowth plants, including forage species, is likely to be greatest on such sites. Although a single rate and placement treatment could be prescribed for pinyon in either ecoregion, juniper trees 
still require more intrasite adjustment.

Possible causes of size-based differences include changes in growth rate with age, increases in litter depth and nonwettability beneath crowns as trees age, and greater interception and concentration of rain and snowfall beneath larger trees (Young et al. 1984, Van Pelt and West 1989). Perhaps the best explanation for the greater tolerance of the smallest 2 size classes to tebuthiuron would be that "smaller trees...generally have denser crowns with more foliage biomass per unit of crown volume or unit of basal area than...larger trees" (Tausch and Tueller 1988:43). The size-based differences evident here were too small to warrant special adjustments for large or small trees during practical retreatment operations.

\section{Linearity of Dosage Effects}

At EC, the ranking of rates by their effect depended on the levels of other factors. Application rate was involved in numerous interactions. In no instance were all the rates discrete in effect. The 2 highest ones were nearly always indistinguishable (especially with pinyon). This signified a defoliation asymptote (saturation) at some level below the maximum used. At both sites, the low rate was usually clearly distinguishable as having the least effect. Formal tests for linear, quadratic, and cubic effects on response were performed for selected factor levels (Steel and Torrie 1980). Linear effects predominated, but the stepped rates very rarely produced graphically equispaced responses. Most of the linearity is contributed by the 2 lowest rates.

\section{Placement-Induced Differences and Convergence of Effects}

Placement differences are the most explanable of the main effects at either site. The midcrown is the most sheltered from rain and snow, has considerable litter, and probably has few fine tree roots beneath it. The dripline is by far the most exposed, and lateral roots must extend to and beyond the crown margin. The stem base is about as sheltered as the midcrown, but water from stemflow concentrates there and can be intercepted by many fine roots (Young et al. 1984).

Consistent placement at the stem base over a project area will result in the lowest proportion of the area with tebuthiuron residues. Furthermore, it will best conceal relatively large particles from animals and humans. Stem base placement can be eased by dropping boluses through an inclined plastic pipe about 1-m long. Other work we reported from these sites (Van Pelt and West 1990) demonstrated the operational superiority of the stembase placement. Its use minimizes the tediousness of application, the time spent applying tebuthiuron particles to each tree, and defoliation of shrubs and grasses underneath. Our findings apply to trees of all sizes within the range of canopy volumes we treated.

Nonetheless, some placements in combination with the same rate evoked indistinguishable responses at all recording occasions. The 4 rates applied to the stem base diverged in effect throughout the intermediate $(12,20$, and 24-month) occasions, but became statistically indistinguishable by 32 months (Fig. 2). Rate and placement differences probably become subdued simply because, given sufficient time, tebuthiuron suffuses through the root zones of the trees. In these climates, it takes nearly 3 years for convergence to become strongly apparent, however.

Trees of the same size, at 1 site, that are dosed identically do respond differently. This probably indicates the vagaries of rooting patterns and tebuthiuron uptake rather than inherently different tolerances. Thus, there was substantial error not attributable to the explicitly tested factors. Somewhat variable results will unavoidably afflict treatment operations, especially when Utah juniper are numerous. The advisability of followup operations would follow from economic analysis of the costs versus benefits of total tree control (Auld et al. 1987), and from derivation of a response surface involving species, rate, and time-since-treatment (Box and Draper 1987).

\section{Hypotheses and Ecoregional Differences}

We did not devise a 'crucial'experiment to test a single hypothesis nor to discern the existence of a particular process or driving variable. Rather, we conducted it in agreement with Quinn and Dunham (1983:604):

The objective of investigation in cases of this sort is not to determine the single cause of a pattern, as no such cause exists, but rather to assign relative importances to the contributions of, and interactions between, a number of processes, all known or reasonably suspected of operating to some degree.

We confirmed that all tested factors were more or less influential, with their contributions both site- and time-dependent. If those attempting broadscale tree control wait long enough, some initial differences will "even out" (Hypothesis (iv) was retained). Treatment plans could thus concentrate on methods of getting herbicide to the trees efficiently, rather than on selection of an "ideal" rate.

We achieved our goal of specifying optimal treatment combinations, especially those manipulable by project planners. We accepted our hypothesis of strong species effects, but rejected those of linear defoliation response and large placement-based differences. The reality of size-based differences was more ambiguous.

The major difference in main effects between the 2 provinces was the greater disparity between Utah juniper and singleneedle pinyon defoliation at Black Rock Canyon than for juniper and Rocky Mountain pinyon at East Carbon. Since a different pinyon species grew at the latter site, any such difference (slight in practical terms) is not truly indicative of "ecoregion" influences (climates and soils). Pinyon species and site were unavoidably confounded. Other differences between sites after 36 months were evident in the ANOVA, but total variance was quite similar throughout.

The balanced experimental design, similar precipitation, and nearly identical amounts of herbicide applied provided a firm basis for comparing results from 2 ecoregions. The patterns of response of BRC and EC displayed some consistent similarities. Assuming the same rainfall and herbicide inputs, our proposed hypothesis is that rangeland sites mediate or apportion an equal total variance through soil differences. A site's response will reflect a greater or lesser emphasis on "natural" (species and size) versus "induced" (rate and placement) factors.

\section{Literature Cited}

Auld, B.A., K.M. Lenz, and C.A. Tisdell. 1987. Weed control economics. Academic Press, London.

Box, G.E.P., and N.R. Draper. 1987. Empirical model-building and response surfaces. John Wiley and Sons, New York.

Clary, W.P, S. Goodrich, and B.M. Smith. 1985. Response to tebuthiuron by Utah juniper and mountain big sagebrush communities. J. Range Manage. 38:56-60.

Cook, C.W., and J. Stubbendieck (eds.) 1986. Range research: basic problems and techniques. Soc. Range Manage., Denver, Colo.

Duncan, K.W., and C.J. Scifres. 1983. Influence of clay and organic matter of rangeland soils on tebuthiuron effectiveness. J. Range Manage. 36:295-297.

Gross, K.L. 1989. Report on "The Experimental Manipulation of Natural Plant Communities: What Have We Learned and What Remains to be Learned? A symposium organized by Jessica Gurevitch. ESA annual meeting, Toronto, Canada, August. 1989". Bull. Ecol. Soc. Amer. 70:263-265.

Herbel, C.H., H.L. Morton, and R.P. Gibbens. 1985. Controlling shrubs in the arid Southwest with tebuthiuron. J. Range Manage. 38:391-394.

Hurlbert, S.H. 1984. Pseudoreplication and the design of ecological field experiments. Ecol. Monogr. 54:187-211.

Hurst, R.L. 1986. Factorial analysis of variance/covariance (FCT-FCTN). Department of Applied Statistics, Utah State Univ., Logan.

Klute, A. (ed.) 1986. Methods of soil analysis. Part I. Physical and mineralogical methods. 2nd ed. Soil Sci. Soc. Amer. Madison, Wis. 
Mize, C.W., and R.C. Schultz. 1985. Comparing treatment means correctly and appropriately. Can. J. For. Res. 15:1142-1148.

Omernik, J.M. 1987. Ecoregions of the United States. Annals Assoc. Amer. Geogr. 77:118-125.

Pearce, S.C., and A.H.F. Brown. 1983. The agricultural field experiment: a statistical examination of theory and practice. John Wiley and Sons, Chichester, U.K.

Provenza, F.D. 1991. Viewpoint: Range science and range management are complementary but distinct endeavors. J. Range Manage. 44:181-183.

Quinn, J.F., and A.E. Dunham. 1983. On hypothesis testing in ecology and evolution. Amer. Natur. 122:602-617.

Scifres, C.J. 1977. Herbicides and the range ecosystem: residues, research, and the role of rangemen. J. Range Manage. 30:86-91.

Soil Conservation Service. 1988. Soil survey of Carbon County, Utah. USDA, SCS, Washington, D.C.

Steel, R.G.D., and J.H. Torrie. 1980. Principles and procedures of statistics. McGraw-Hill Book Co., N.Y.

Tausch, R.J., and P.T. Tueller. 1988. Comparison of regression methods for predicting singleleaf pinyon phytomass. Great Basin Natur. 48:39-45.
Van Pelt, N.S. 1988. Dynamics and control of tree regrowth on previously cleared pinyon-juniper woodland sites in Utah. Ph.D. Diss., Utah State Univ., Logan.

Van Pelt, N.S., and N.E. West. 1989. Aboveground dissolution of tebuthiuron particles placed beneath the crowns of small pinyon. trees. $J$. Environ. Qual. 18:281-284.

Van Pelt, N.S., and N.E. West. 1990. Effects of manual application method on application time, thoroughness and tebuthiuron outlays. J. Range Manage. 43:39-42.

Warren, W.G. 1979. Analysis and interpretation of an experiment with a heterogeneous mixture of treatment types. Biometrics 35:869-872.

West, N.E. 1984. Successional patterns and productivity potentials of pinyon-juniper ecosystems, p. 1301-1332. In: Nat. Acad. Sci./Nat. Res. Council. Developing Strategies for Rangeland Management. Westview Press, Boulder, Colo.

Yang, R.C. 1983. Composite design versus factorial experiments in forest fertilization trials. Can. J. Forest. Res. 13:438-444.

Young, J.A., R.A. Evans, and D.A. Easi. 1984. Stem flow on western juniper (Juniperus occidentalis) trees. Weed Sci. 32:320-327. 